\title{
A Critical Assessment of the Roles of Circulating Hydrogen Ion and Lactate in the Production of Exercise-Induced Asthma
}

\author{
Richard H. Strauss, R. H. Ingram, JR., and E. R. MCFAdDEn, JR. \\ From the Departments of Medicine of Peter Bent Brigham Hospital and Harvard Medical School, \\ Boston, Massachusetts 02115
}

A B S T RA C T To evaluate the roles of circulating hydrogen ion and lactate in the production of exerciseinduced asthma, two experiments were performed. In the first, we exercised six asthmatic subjects to exhaustion on a bicycle ergometer while recording arterial $\mathrm{pH}$ at periodic intervals. Multiple aspects of pulmonary mechanics were measured before and after the work load. After recovery, the identical procedures were repeated, but sufficient quantities of sodium bicarbonate were infused to keep the $\mathrm{pH}$ at the preexercise level. In both experiments, statistically identical attacks of asthma were induced. To study the effect of lactate, five subjects were exercised on several occasions in order to determine the lowest level of work, and hence arterial lactate, that was reproducibly associated with an acute asthma attack. When this was known, sufficient quantities of sodium lactate were infused into the resting subjects so as to equal or exceed the amount produced with exercise. Pulmonary mechanics were not altered with this intervention. These findings demonstrate that lactic acidemia is not the cause of exercise-induced asthma.

\section{INTRODUCTION}

Many authorities feel that the development of acute exacerbations of asthma after physical exertion is somehow related to humoral factors being generated and/or released by the exercising muscles, and it has been suggested that the cause is lactic acidosis (1). For a number of reasons, this is an attractive hypothesis. First, the association between the induction of asthma and elevations in arterial hydrogen ion and/or lactate concentrations is quite common when one searches for it in the literature $(1-11)$. Second, because the acid

Received for publication 5 January 1977 and in revised form 22 April 1977. end products of exercise are delivered to the airways and lung parenchyma by the bronchial and pulmonary arterial beds, and are freely permeable, they could possibly evoke intracellular events that promote generation or release of the mediators of immediate hypersensitivity (12-14). Unfortunately, this hypothesis has not been critically evaluated to date, and the contributions of hydrogen ion and lactate to the bronchospastic response have not been systematically studied.

In the present investigation two sets of experiments were performed to determine the roles of these two variables. In the first, sodium bicarbonate was infused to prevent the acidosis associated with exercise. In the second, sodium lactate was administered at rest. The results of these studies form the basis of this report.

\section{METHODS}

Five men and six women, all of whom met the American Thoracic Society's definition of asthma (15), served as our subjects. All were atopic and had reproducible exerciseinduced asthma documented in our laboratory. Their mean age was $23.8 \pm 3.2(\mathrm{SD}) \mathrm{yr}$ and none were smokers. All refrained from taking any medication for at least $12 \mathrm{~h}$ before any study day. None had used glucocorticoids or disodium cromoglycate for at least a month before these studies. Informed consent was obtained from each participant.

We measured airway resistance and total lung capacity with its subdivisions in a variable pressure plethysmograph that was serially interfaced to an analogue recorder and a minicomputer $(16,17)$. Resistance was converted to its reciprocal conductance, and expressed as a conductance-volume ratio termed specific conductance $\left(\mathrm{SG}_{\mathrm{A}}\right)^{1}(18)$. Four to five measurements of each variable were obtained and the mean computed. These data were considered acceptable if their coefficients of variation were $5 \%$ of less. Maximum forced

\footnotetext{
${ }^{1}$ Abbreviations used in this paper: $\mathrm{FEV}_{1}, 1-\mathrm{s}$ forced expiratory volume; MMF, maximum mid-expiratory flow rates; $\dot{\mathrm{V}}_{\mathrm{E}}$, minute ventilation.
} 
exhalations were then performed in triplicate with a waterless spirometer (Electro Med model 780, Electro Med, Houston, Tex.). 1-s forced expiratory volumes $\left(\mathrm{FEV}_{\mathbf{i}}\right)$ and maximum mid-expiratory flow rates (MMF) were computed by standard techniques. The best effort, as defined by the curve with the largest forced vital capacity and $\mathrm{FEV}_{1}$, was used for analysis.

All subjects had a radial artery and an antecubital vein cannulated under local anesthesia. Arterial blood was sampled periodically and analyzed for its $\mathrm{pH}$, and partial pressures of oxygen $\left(\mathrm{PaO}_{2}\right)$ and carbon dioxide $\left(\mathrm{PaCO}_{2}\right)$ with a blood gas analyzer (model 113; Instrumentation Laboratory, Inc., Lexington, Mass.) that had been calibrated with gases of known concentrations (19). Arterial lactate concentrations were determined in a DuPont Automatic Clinical analyzer (DuPont Instruments, Wilmington, Del.) using an enzymatic technique (20). This method measures only the amount of the biologically active L-lactate in plasma. The vein was used for infusions of saline, sodium bicarbonate, or sodium lactate.

Expired gas was collected by having the subjects breathe through a low resistance, low dead-space valve into a 120liter Tissot spirometer (Warren E. Collins, Inc., Braintree, Mass.). Tidal volume, respiratory frequency, and heart rate were recorded continuously. Minute ventilation $\left(\dot{\mathrm{V}}_{\mathrm{E}}\right)$ was determined from the expired gas collection.

In the first set of experiments, we investigated the role of circulating $\mathrm{H}^{+}$. This was achieved by having six subjects (three men and three women) perform leg work on a cycle ergometer. An external work load was selected which resulted in exhaustion within 3-6 min. The mean work load was $1,125 \pm 526 \mathrm{kpm} / \mathrm{min}(\mathrm{SD})$ and mean duration was $4.13 \pm 0.97$ min. During exercise and recovery, $150 \mathrm{ml}$ of normal saline was infused by vein as a placebo. This study served as a control. Exhausting work was used so as to obtain large changes in $\mathrm{pH}$.

Pulmonary mechanics were measured before and 5 min after completion of the work load. Ventilation was measured at minute intervals before, during, and after exercise. The data from the last minute of the rest and exercise periods and the 5 th minute of the recovery period were used for analysis. Arterial bloods were sampled simultaneously with expired gas. In addition, they were also collected at 2-min intervals during recovery.

Upon completion of this study, the patients were allowed to rest for at least $1.5 \mathrm{~h}$ while their mechanical function returned toward pre-exercise levels. The experiment was then repeated with each subject using the same work load and duration as previously. However, in this second experiment, sufficient quantities of a $1 \mathrm{meq} / \mathrm{ml}$ solution of $\mathrm{NaHCO}_{3}$ were infused during exercise and recovery to prevent the $\mathrm{pH}$ from falling. The amount infused was estimated from the calculated decrease in $\mathrm{HCO}_{3}{ }^{-}$in the first experiment, and estimates of the size of the extracellular fluid compartment based upon body weight. The mean $\mathrm{HCO}_{3}{ }^{-}$administered was $178 \pm 36$ (SD) meq. Pulmonary mechanics were measured at the same time as in the control experiment.

To evaluate the effects of lactate, a second set of experiments was performed on a different day, with five subjects (two men and three women). This set of studies involved both exercise and lactate infusions. The exercise stimulus consisted of treadmill running at zero grade for $4 \mathrm{~min}$ at constant speeds which ranged from 5 to $6.5 \mathrm{mph}$. This was done so that we would be dealing with the lowest levels of lactate associated with acute airway obstruction. Trials on earlier days had shown that each subject had an acute exacerbation of his asthma with this moderate work load.

Our reasons for changing the work loads were as follows.
Because it is known that infusions of lactate can mimic acute anxiety reactions (21), and given the fact that some asthmatics respond to psychological stress with bronchoconstriction $(22,23)$, it was necessary to determine the highest lactate levels that could be achieved exogenously that would be associated with absent or minimal symptoms. To accomplish this, we performed preliminary experiments by infusing lactate into ourselves. These experiments demonstrated that we could readily achieve arterial levels of 8-12 meq/liter with a minimum of symptoms using a slow rate of infusion. However, when we attempted to reach the levels found with bicarbonate administration (vida infra), symptoms increased significantly if the infusion was fast, and when we slowed it, the lactate levels were found to be low. Consequently, for patient comfort, and to minimize the possibility of inducing psychological effects during the infusion experiments, we chose exercise tasks and work loads that

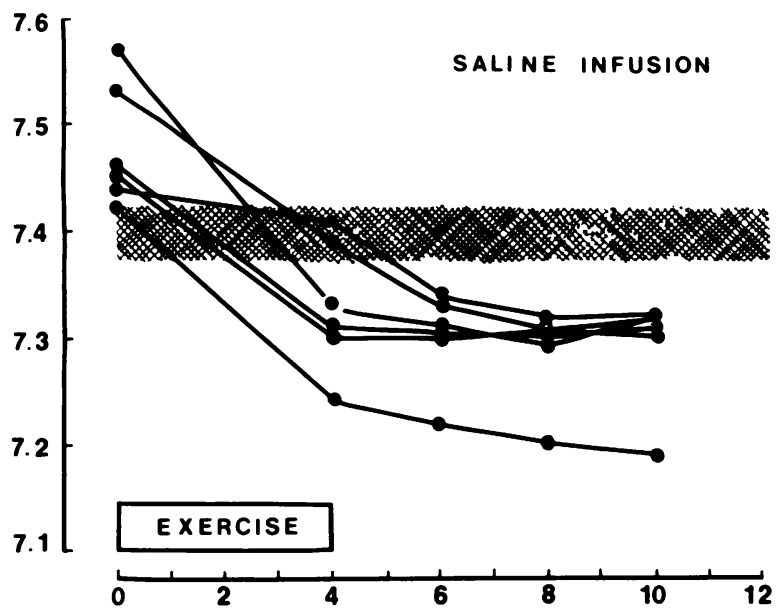

I

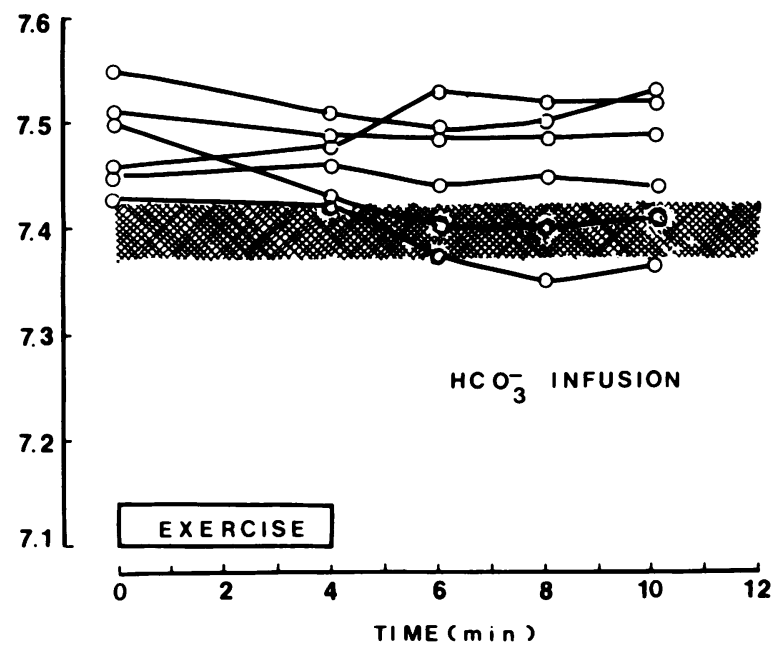

FIgURE 1 Time-course of arterial $\mathrm{pH}$ changes in individual subjects before, during, and after exercise. The closed and open circles represent the control (saline infusion) and bicarbonate $\left(\mathrm{HCO}_{3}^{-}\right)$infusion studies, respectively. The mean duration of exercise is shown by the labeled rectangle. The normal $\mathrm{pH}$ range is indicated by the shaded areas. 


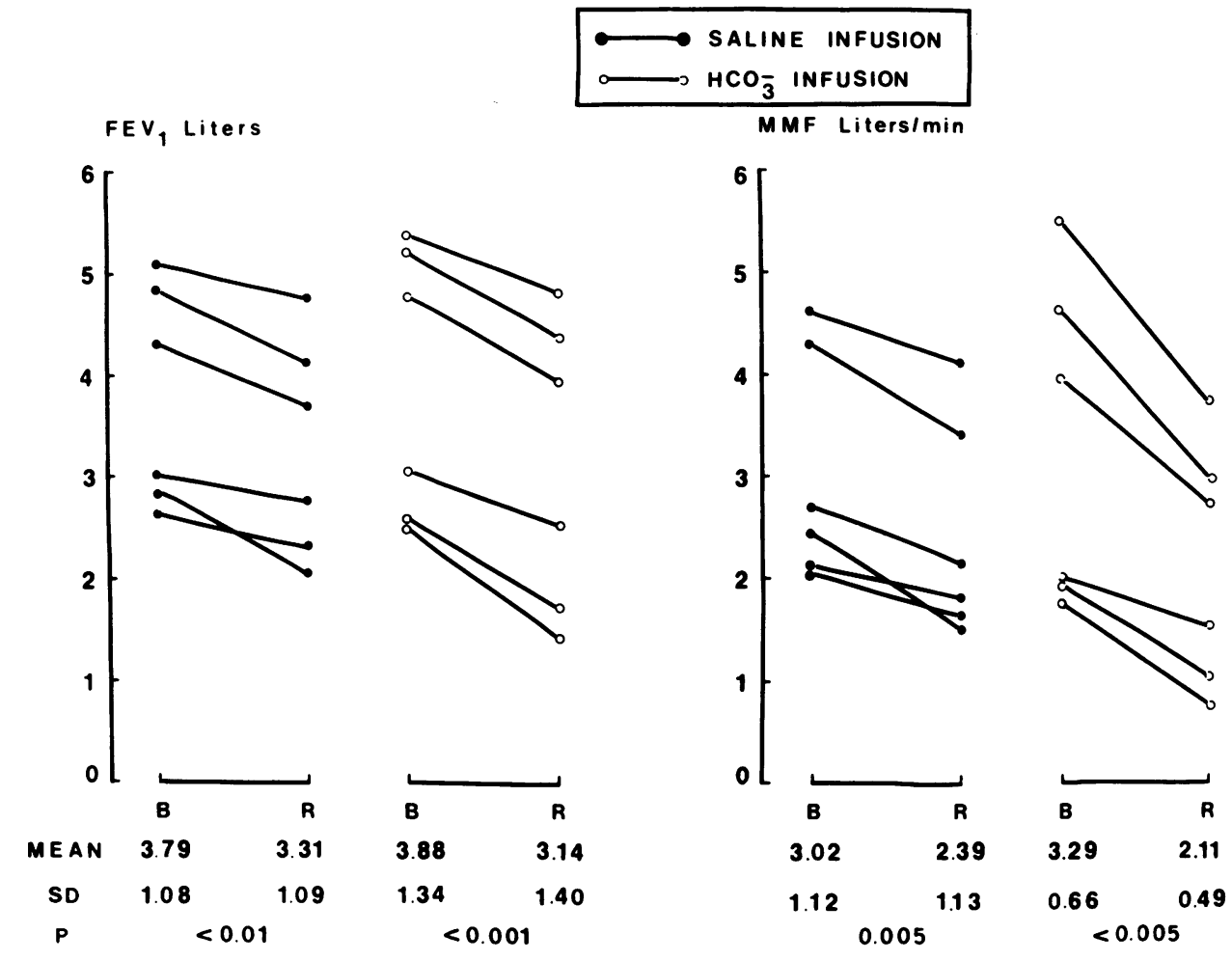

FIGURE 2 Spirometric indices before and after exercise in individual subjects. The letters B and $\mathbf{R}$ indicate the base-line values and the responses observed after cessation of the work load, respectively. The open and closed circles represent the saline and $\mathrm{HCO}_{3}^{-}$experiments. The $P$ values below each graph were derived from base-line response comparisons.

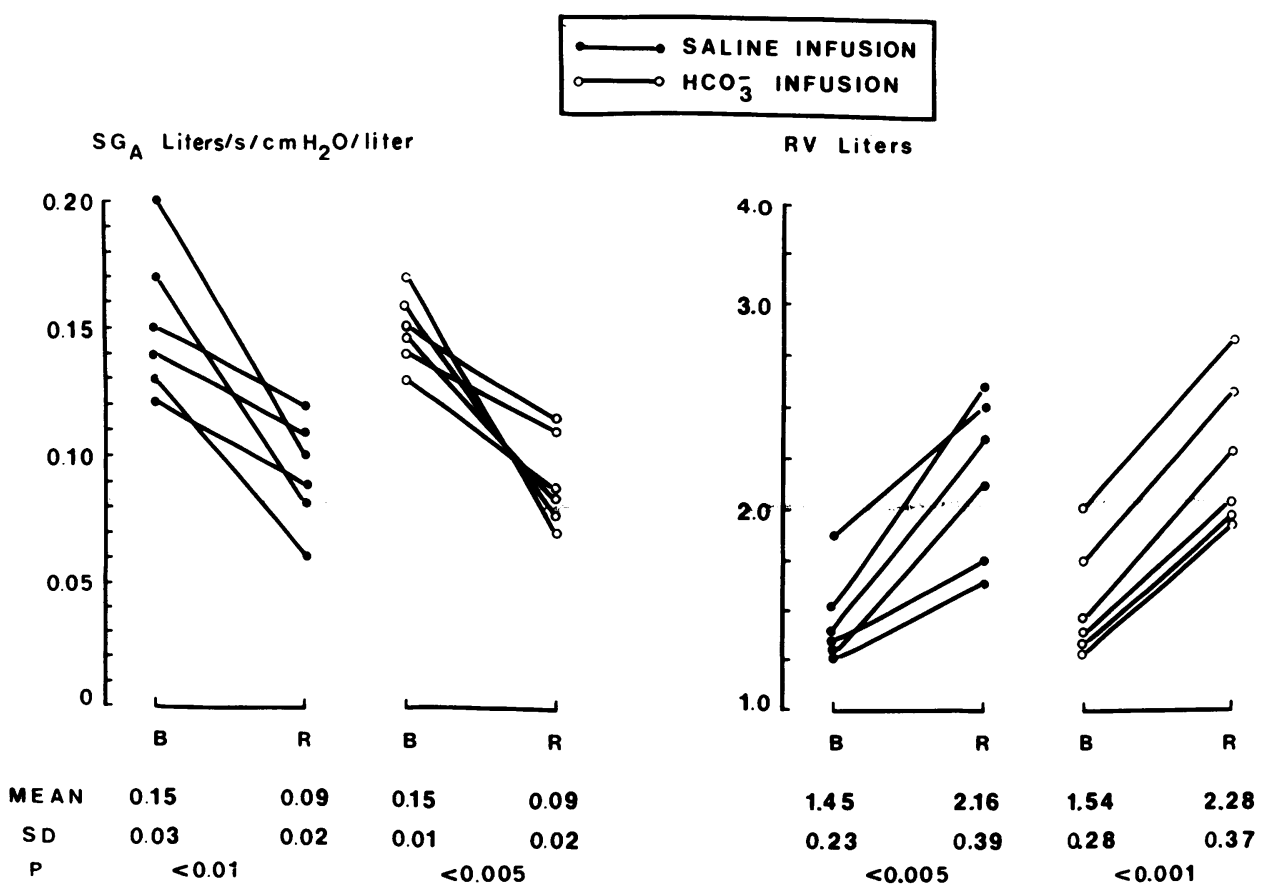

FIGURE 3 Plethysmographic and lung volume indices before and after exercise in individual subjects. RV, residual volume. The format is identical to that of Fig. 2. 
would produce the lowest possible levels of endogenous lactate associated with acute airway obstruction, and that therefore would be the easiest to match exogenously.

In a random sequence, approximately $1.5 \mathrm{~h}$ before (three subjects) or after exercise (two subjects) racemic sodium lactate $(1 \mathrm{meq} / \mathrm{ml})$ was administered by vein over approximately $19 \mathrm{~min}(19.1 \pm 1.7$ [SD] $\mathrm{min})$ into the resting subject. We sought to infuse sufficient $D, L$-lactate so that the peak arterial level of the L-isomer achieved equaled or exceeded the peak observed with treadmill exercise in a given subject. The mean amount of racemic lactate administered was $346 \pm 35$ (SD) meq.

Measurements of spirometry, plethysmography, $\dot{\mathrm{V}}_{\mathrm{E}}$, arterial blood gases, and arterial lactate were made in the sequences described above. The data were analyzed by Student's $t$ tests for paired samples.

\section{RESULTS}

Fig. 1 displays the time-course of the individual $\mathrm{pH}$ changes in the saline and $\mathrm{HCO}_{3}{ }^{-}$infusion studies. In the control and $\mathrm{HCO}_{3}^{-}$infusion experiments, five of the six subjects had a respiratory alkalosis before initiating exercise, so that any effect of hypocapnia on airway dimensions would have been equal in both experiments. During saline infusion, all subjects developed significant acidemia with the lowest $\mathrm{pH}$ values occurring between the 4th and 5th min of the recovery period (base-line $\mathrm{pH}=7.48 \pm 0.06$ $[$ mean $\pm \mathrm{SD}$ ]; 4 th $\mathrm{min}$ postexercise $\mathrm{pH}=7.29 \pm 0.04$; $t=7.89 ; P<0.001$ ). Arterial $\mathrm{pH}$ had begun to fall by the 2 nd min of exercise (base-line $\mathrm{pH}=7.48 \pm 0.06$; 2nd $\min$ of exercise $\mathrm{pH}=7.40 \pm 0.04 ; t=4.01$; $P<0.01$ ). Infusion of $\mathrm{HCO}_{3}{ }^{-}$abolished this response (base-line $\mathrm{pH}=7.48 \pm 0.04 ; 2 \mathrm{nd}$ min of exercise $\mathrm{pH}$ $=7.47 \pm 0.03 ; 4$ th $\mathrm{min}$ postexercise $\mathrm{pH}=7.45 \pm 0.07$; base line vs. 2nd $\mathrm{min}$ of exercise $t=0.98 ; P$, NS; base line vs. 4th $\min$ of recovery $t$ test $=1.36$; $P, \mathrm{NS})$. In only one subject in the $\mathrm{HCO}_{3}{ }^{-}$experiment did the $\mathrm{pH}$ fall below the normal range, and in this individual the lowest value recorded was 7.35 compared with 7.20 in the control study.

The pulmonary mechanical response to exercise during both experiments is shown in Figs. 2 and 3. In the control study, there were marked alterations in every measured parameter of lung function. $\mathrm{FEV}_{1}$, MMF (Fig. 2), and $\mathrm{SG}_{\mathrm{A}}$ (Fig. 3) all fell. Residual volume rose (Fig. 3). These changes were significant at the $1 \%$ level or less. The data in these figures also demonstrate that there were no significant differences between experiments in the prechallenge values for any of the indices measured. Thus, recovery from the effects of the first study was complete before the second was initiated. Bicarbonate administration did not influence the degree of bronchoconstriction produced by exercise even though the acidemia was prevented.

Bicarbonate infusion was associated, however, with significantly higher exercise and recovery arterial

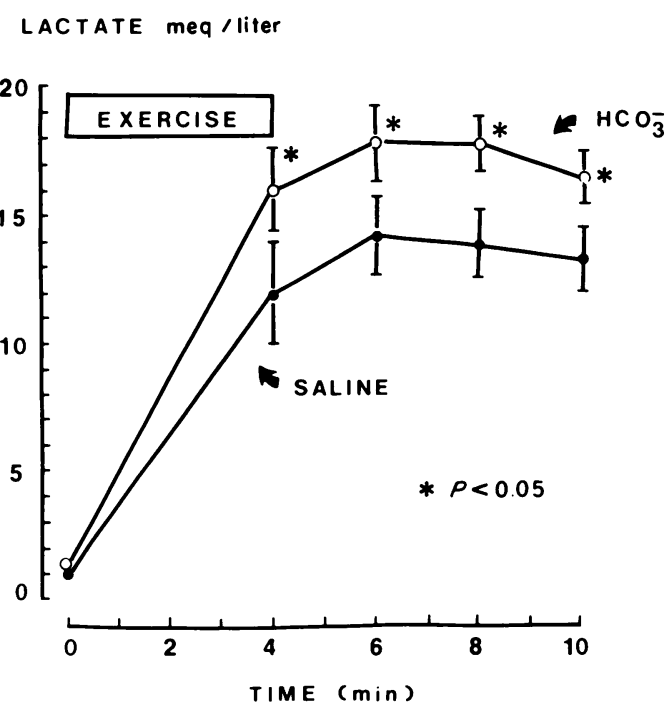

FIgure 4 Time-course of changes in arterial lactate. The open and closed circles represent the bicarbonate $\left(\mathrm{HCO}_{3}{ }^{-}\right)$ and control experiments (saline), respectively. The data points are mean values and the brackets represent $1 \mathrm{SE}$. The asterisks indicate significant differences from the saline study.

lactates (Fig. 4), and $\mathrm{PaCO}_{2}$ values (Fig. 5). $\dot{\mathrm{V}}_{\mathrm{E}}$ during exercise was slightly less in the $\mathrm{HCO}_{3}{ }^{-}$study but the difference did not reach statistical significance (Fig. 5).

The data from the lactate infusion experiments are
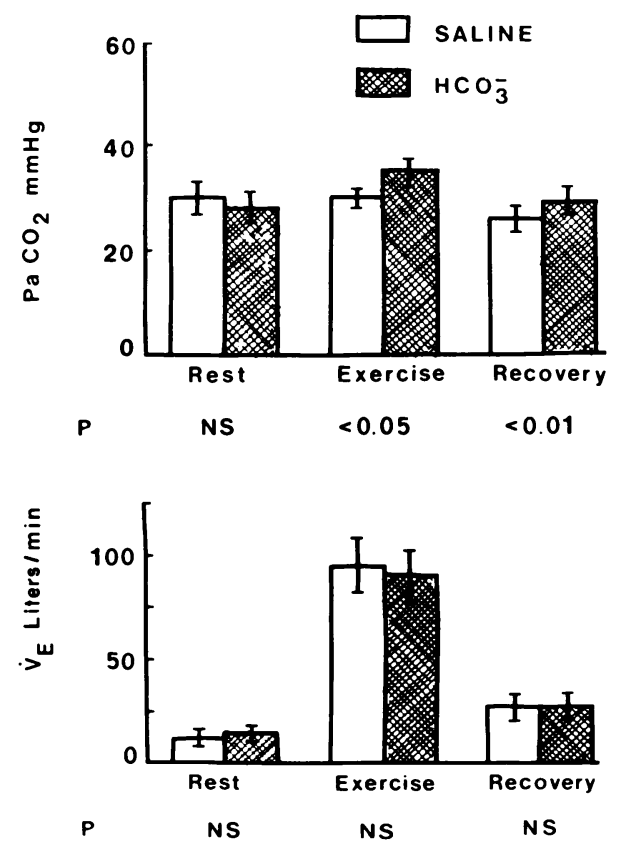

Figure 5 Arterial carbon dioxide $\left(\mathrm{PaCO}_{2}\right)$ and $\dot{\mathrm{V}}_{\mathrm{E}}$ before, during, and after exercise. The open bars show the saline infusion data and the shaded bars represent the bicarbonate study. The heights of the bars indicate mean values and the brackets $1 \mathrm{SE}$. The $P$ values refer to saline- $\mathrm{HCO}_{3}{ }^{-}$comparisons. 

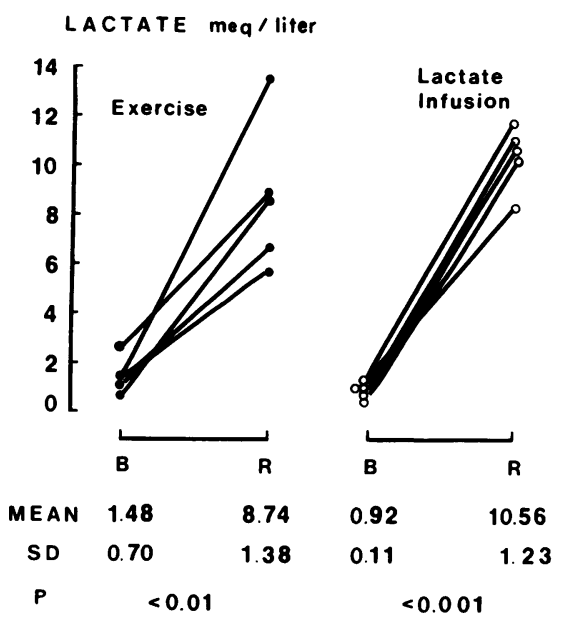

FIgURE 6 Individual arterial lactate concentrations with treadmill exercise $(-0)$ and lactate infusion experiments $(O-O)$. The letters $B$ and $R$ indicate the baseline and peak response values, respectively. The $P$ values represent base-line response comparisons.

presented in Figs. 6 through 8. The base-line and peak lactates associated with exercise and infusion are shown in Fig. 6. In both instances peak levels were significantly greater than resting values. In the exercise study, the highest concentrations occurred within 2 min after cessation of work. In the infusion experiments, the maximum value was found near the end of the infusion. Thus the time-course of reaching peak values varied between the two studies. However, there were no significant differences between the absolute levels observed (peak exercise mean \pm SD $=8.74 \pm 1.38 ;$ infusion $=10.56 \pm 1.23 \mathrm{meq} / \mathrm{liter} ; t$ $=1.13 ; P$, NS). In only one subject was the exercise level higher than the infusion value and the difference was $3.3 \mathrm{meq} / \mathrm{liter}$.

The data in Figs. 7 and 8 show that the baseline values for mechanics were slightly worse in this study than in the $\mathrm{HCO}_{3}{ }^{-}$experiments. Presumably this represents spontaneous variation in the underlying activity of the disease in the interval between study days. Nonetheless, the critical factor is that the baseline values for the lactate and exercise studies were statistically identical, and exercise precipitated an asthmatic response, whereas duplication of the values of arterial lactate produced by exercise with exogenous infusion was without any effect on mechanical lung function.

Lactate administration was associated with mild discomfort at the site of infusion, circumoral and arm and leg paresthesias, light-headedness and thirst. The neurological symptoms were believed to be the result of systemic alkalemia. During the lactate infusion, $\mathrm{pH}$ rose from a mean value of $7.44 \pm 0.04$ (SD) to $7.59 \pm 0.06 ; P<0.005$. The thirst was secondary to the high osmolarity of the sodium lactate solution. Bicarbonate infusions were not associated with any symptoms.

\section{DISCUSSION}

Previous work from this (2) and other laboratories (1, 3-11) has shown that postexertional bronchocon-

\section{EXERCISE \\ LACTATE INFUSION}

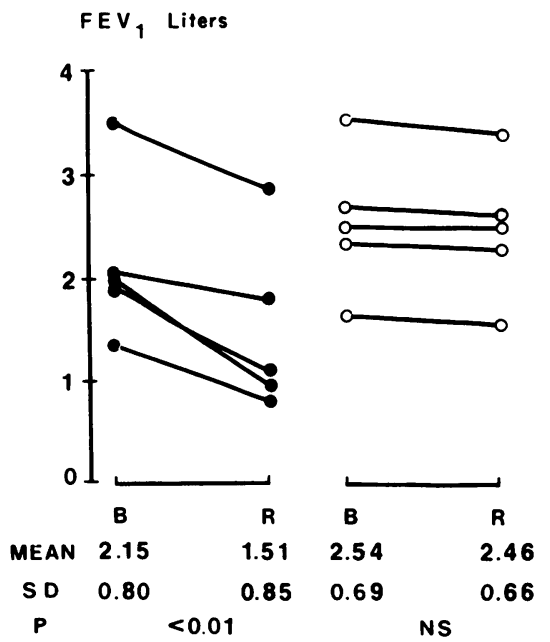

MMF Liters/min

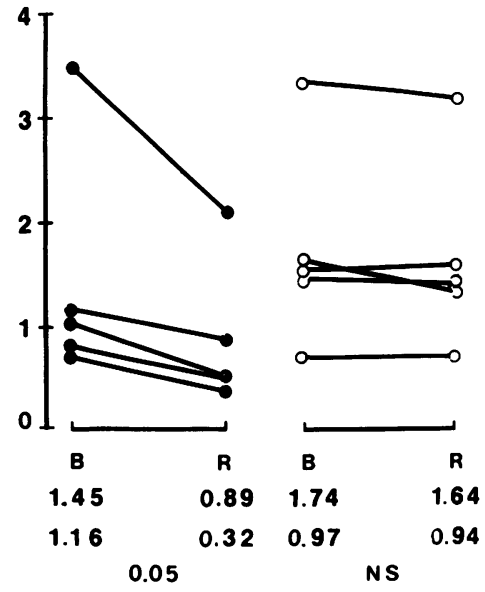

FIGURE 7 Spirometric indices before and after treadmill exercise $\left(O_{-}\right)$and lactate infusions $(O-O)$ in individual subjects. The $P$ values below each graph represent baseline (B) response (R) comparisons. 


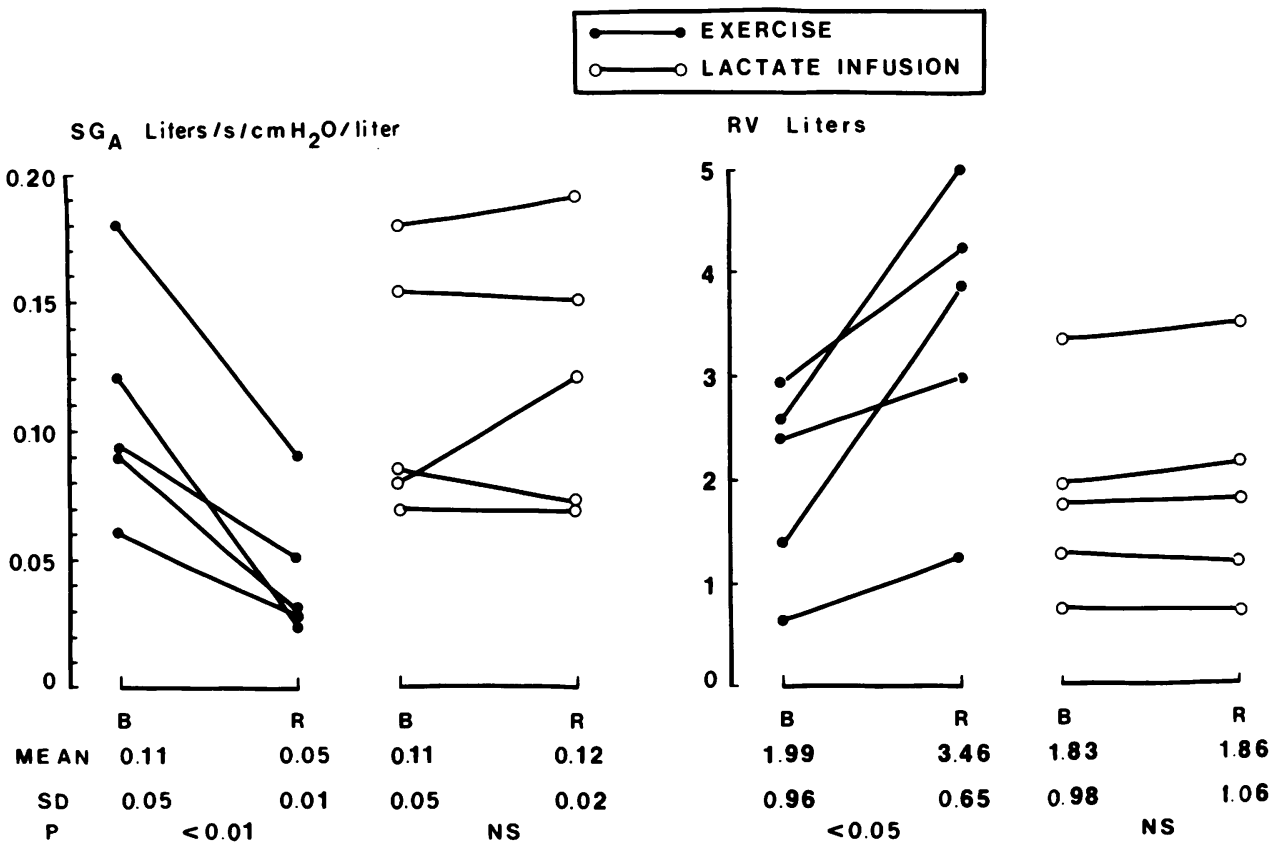

FIGURE 8 Plethysmographic and lung volume indices before and after treadmill exercise $(-)$ ) and lactate infusions $(\mathrm{O}-\mathrm{O})$ in individual subjects. $\mathrm{RV}$, residual volumes. The $P$ values below each graph represent base-line $(B)$ response $(\mathrm{R})$ comparisons.

striction in asthmatics can be related to the increases in arterial hydrogen ion concentrations that result from the end products of anaerobic metabolism, and practically never occurs without such changes. These findings raise the question as to associative versus causative roles. The present study clearly documents that exercise-induced asthma occurs even when the acidemia is prevented. Thus the level of circulating hydrogen ion presented to the lungs is not causally related to the development of airway obstruction. In addition, when the highest lactate concentrations found with exercise were reproduced by infusions at rest, no detectable change in lung function occurred. Consequently, it appears that lactate itself does not cause exercise-induced asthma either and it is unlikely that it is a contributory factor.

One question that must remain unanswered at this time is whether acidosis secondary to anaerobic metabolism at the intracellular level in the working muscles is the key stimulus. Pulmonary effects could then possibly result from two mechanisms: the release of some humoral metabolite other than lactic acid, or stimulation of somatic afferent nerves with activation of pulmonic efferents. To date, there is no information at all in the literature regarding the first point. With respect to the second possibility, although it is known that both electrical stimulation of afferent nerve fibers from resting limbs (24) and perfusion of isolated skeletal muscle with hyperkalemic blood when the nerve is intact $(25)$ produce an increase in ventila- tion typical of exercise, recent evidence demonstrates that neither hypocapnia nor hyperpnea are the mechanisms underlying exercise-induced asthma (26).

It is possible, however, that through some central process, vagal efferents could be activated by somatic neural input and on that basis produce reflex bronchospasm. We believe this to be unlikely because although some of the patients in this study have their response to exercise abolished with pretreatment with parasympatholytic agents (27), these same individuals have their bronchoconstriction blunted with disodium cromoglycate (28). Inasmuch as this drug is not a bronchodilator but acts largely as an inhibitor of mediator release (29), it seems that under these circumstances reflex bronchospasm may be due to the local release of the mediators of immediate hypersensitivity in the vicinity of irritant receptors.

Another question that remains unanswered by the present study is whether exogenously infused lactate could interact positively with aerobic exercise that was insufficient by itself to cause bronchospasm. Although there is precedent for the interaction of subthreshold stimuli to cause the development of airway obstruction in normals and asthmatics (30-32), all of the stimuli used to date in these studies are bronchoconstrictors in and of themselves. Our data demonstrate that lactate in reasonably high levels does not have this property. Consequently, the above possibility seems unlikely as well.

Irrespective of the final common pathway, it now 
seems clear that lactic acidemia per se is not a causative factor in exercise-induced asthma, but rather a temporal associate. As such it is a useful index to insure that sufficient work has been performed to induce changes in pulmonary mechanics.

\section{ACKNOWLEDGMENTS}

This work was supported in part by Research Career Development Award HL00013 (E.R. McF.) and grants HL17873, HL17382, and HL07010 from the National Heart and Lung Institute.

\section{REFERENCES}

1. Vassallo, C. L., J. B. L. Gee, and B. M. Domm. 1972. Exercise-induced asthma. Am. Rev. Respir. Dis. 105: 4249.

2. Strauss, R. H., R. L. Haynes, R. H. Ingram, Jr., and E. R. McFadden, Jr. 1977. Comparison of arm versus leg work in the induction of acute episodes of asthma. J. Appl. Physiol. 42: 565-570.

3. Barboriac, J. J., A. J. Sosman, J. N. Fink, M. G. Maksud, L. H. McConnell, and L. H. Hamilton. 1973. Metabolic changes in exercise-induced asthma. Clin. Allergy. 3: 8389.

4. Chan-Yeung, M. M. W., M. N. Vyas, and S. Grzybowski. 1971. Exercise-induced asthma. Am. Rev. Respir. Dis. 104: 915-923.

5. Griffiths, J., F. Y. Leung, S. Grzybowski, and M. M. W. Chan-Yeung. 1972. Sequential estimation of plasma catecholamines in exercise-induced asthma. Chest. 62: 527533.

6. Fisher, H. K., P. Holton, R. St. J. Buxton, and J. A. Nadel. 1970. Resistance to breathing during exercise-induced asthma attacks. Am. Rev. Respir. Dis. 101: 885-896.

7. Katz, R. M., B. J. Whipp, E. M. Heimlich, and K. Wasserman. 1971. Exercise-induced bronchospasm, ventilation and blood gases in asthmatic children. J. Allergy. 47: $148-158$.

8. Rebuck, A. S., and J. Read. Exercise-induced asthma. 1968. Lancet. 1: 429-431.

9. Seaton, A., G. Davies, D. Gaziano, and R. O. Hughes. 1969. Exercise-induced asthma. Br. Med. J. 3: 556-558.

10. Silverman, M., S. D. Anderson, and S. R. Walker. 1972. Metabolic changes preceding exercise-induced bronchoconstriction. Br. Med. J. 1: 207-209.

11. Simonsson, B. G., B-E. Skoogh, and B. Ekstrom-Jodal. 1972. Exercise-induced airways constriction. Thorax. 27: $169-180$.

12. Brocklehurst, W. E. 1967. Pharmacologically active substances in hypersensitivity reactions. In Modern Trends in Immunology. Vol. II. R. Cruickshank and D. M. Weir, editors. Butterworth, Co. Ltd., London. 236-249.

13. Lewis, G. P. 1968. Kinins. J. R. Coll. Physicians Lond. 2: 353-358.

14. Bach, M., K. J. Bloch, and K. F. Austen. 1971. IgE and IgGA antibody-mediated release of histamine from rat peritoneal cells. I. Optimum conditions for in vitro preparation of target cells with antibody and challenge with antigen. J. Exp. Med. 133: 752-771.

15. American Thoracic Society. 1962. Definitions and classifications of chronic bronchitis, asthma and pulmonary emphysema. Am. Rev. Respir. Dis. 85: 762-768.
16. DuBois, A. B., S. Y. Botelho, G. N. Bedell, R. Marshall, and J. H. Comroe, Jr. 1956. A rapid plethysmographic method for measuring thoracic gas volume: a comparison with a nitrogen washout method for measuring functional residual capacity in normal subjects. J. Clin. Invest. 35: 322-326.

17. DuBois, A. B., S. Y. Botelho, and J. H. Comroe, Jr. 1956. A new method for measuring airway resistance in man using a body plethysmograph: values in normal subjects and in patients with respiratory disease. J. Clin. Invest. 35: 327-335.

18. Briscoe, W. A., and A. B. DuBois. 1958. The relationship between airway resistance, airway conductance and lung volume in subjects of different age and body size. $J$. Clin. Invest. 37: 1279- 1285.

19. Scholander, P. F. 1947. Analyzers for accurate estimation of respiratory gas in one-half cubic centimeter samples. J. Biol. Chem. 167: 235-250.

20. Marbach, E. P., and M. H. Weil. 1967. Rapid enzymatic measurement of blood lactate and pyruvate: use and significance of metaphosphoric acid as a common precipitant. Clin. Chem. 13: 314-325.

21. Pitts, F. N., and J. N. McClure. 1967. Lactate metabolism in anxiety neurosis. N. Engl. J. Med. 277: 13291336.

22. Luparello, T., H. A. Lyons, E. Bleeker, and E. R. McFadden, Jr. 1968. Influences of suggestion on airway reactivity in asthmatic subjects. Psychosom. Med. 30: 819-825.

23. McFadden, E. R., Jr., T. Luparello, H. A. Lyons, and E. Bleeker. 1969. The mechanism of action of suggestion in the induction of acute asthma attacks. Psychosom. Med. 81: 134-143.

24. Senapati, J. M. 1966. Effect of stimulation of muscle afferents on ventilation of dogs. J. Appl. Physiol. 21: 242246.

25. Wildenthal, K., D. S. Mierzwiak, N. S. Skinner, Jr., and J. H. Mitchell. 1968. Potassium-induced cardiovascular and ventilatory reflexes from the dog hindlimb. Am.J. Physiol. 215: 542-548.

26. McFadden, E. R., Jr., D. R. Stearns, R. H. Ingram, Jr., and D. E. Leith. 1977. Relative contributions of hypocarbia and hyperpnea as mechanisms in post-exercise asthma. J. Appl. Physiol. 42: 22-27.

27. McFadden, E. R., Jr., R. H. Ingram, Jr., R. L. Haynes, and J. J. Wellman. 1977. Predominant site of flow limitation and mechanisms of postexertional asthma. J. Appl. Physiol. 42: 746-752.

28. Haynes, R. L., R. H. Ingram, Jr., and E. R. McFadden, Jr. 1976. An assessment of the pulmonary response to exercise in asthma and an analysis of the factors influencing it. Am. Rev. Respir. Dis. 114: 739-752.

29. Goodman, L. S., and A. Gilman. 1975. The pharmacologic basis of therapeutics. The Macmillan Company, New York. 602 .

30. Mitchell, C., and A. Bouhuys. 1976. Interaction between bronchoconstrictor stimuli on human airway smooth muscle. Yale J Biol. Med. 49: 317-325.

31. Orehek, J., J. P. Massari, P. Gayrard, C. Grimaud, and J. Charpin. 1976. Effect of short-term, low level nitrogen dioxide exposure on bronchial sensitivity of asthmatic patients. J. Clin. Invest. 57: 301-307.

32. Orehek, J., P. Gayrard, C. Grimaud, and J. Charpin. 1975. Effect of maximal respiratory manoeuvers on bronchial sensitivity of asthmatic patients as compared to normal people. Br. Med.J. 1: 123-125. 